\title{
ASPECTOS DA REGULAÇÃO SOBRE O ENSINO A DISTÂNCIA NO BRASIL
}

\author{
Nirave Reigota Caram ${ }^{1}$ \\ José Luís Bizelli²
}

\begin{abstract}
RESUMO: O presente artigo apresenta uma reflexão em torno dos aspectos históricos e de legislação sobre Ensino a Distância (EAD). Para tanto, foi realizada uma investigação bibliográfica e documental com o objetivo de levantar os apontamentos necessários para a discussão. O texto inicia-se com a caracterização da sociedade atual, a Sociedade da Informação, que ampara o EAD moderna, a qual utiliza as tecnologias de informação e comunicação (TIC) para estabelecer o processo de ensino aprendizagem. Cinco fases do EAD são identificadas. Posteriormente, a legislação brasileira referente ao EAD é pontuada, iniciando com a passagem pelo Art. 80 da Lei de Diretrizes e Bases - LBD (Lei 9394/96) juntamente com a análise crítica do Decreto 5.622/05. Por fim, nas considerações finais é discutida a imagem negativa que o EAD carrega por parte da população brasileira e entraves nas normas vigentes que dificultam a democratização do acesso à Educação que o EAD objetiva.
\end{abstract}

Palavras-chave: Ensino a Distância; História do EAD; Legislação do EAD; Democratização da Educação.

\begin{abstract}
This article presents a reflection on the historical aspects and legislation on Distance Learning (DL). For this, a bibliographic and documentary research was performed with the goal of raising the necessary notes for discussion. The text begins with the characterization of the current society, the Information Society, which supports the modern distance education, which uses information and communication technologies (ICTs) to establish the process of learning teaching. Five stages of the EAD are identified. Later, the Brazilian legislation concerning the DL is punctuated, starting with the passage by Article 80 of the Guidelines and Bases Law -. LBD (Law 9394/96) along with the critical analysis of Decree 5,622 / 05. Finally, in the final considerations is discussed the negative image that the DL carries by the Brazilian population and obstacles in the existing rules that hinder the democratization of access to education that aims DL.
\end{abstract}

Keywords: Distance Education; History of DL; DL legislation; Education Democratization.

\section{Introdução}

A sociedade atual é configurada por Castells (1999) como Sociedade da Informação, caracterizada por diversidade social, econômica e cultural, a sociedade na qual a informação passou a ser o produto mais valioso. Limites estruturais e possibilidades estão postos para enfrentar os desafios da inclusão cidadã por meio de uma educação inovadora que incorpore as Tecnologias de Informação e Comunicação (TIC), hoje disponíveis na sociedade brasileira (BIZELLI, 2013).

\footnotetext{
${ }^{1}$ Doutoranda do Programa de Pós-Graduação de Educação Escolar da Universidade Estadual Paulista, Faculdade de Ciências e Letras, FCLAr-UNESP, CEP: 14800-901, Araraquara - SP, Brasil, email: nira rc@ hotmail.com

${ }^{2}$ Professor Adjunto da Universidade Estadual Paulista, Faculdade de Ciências e Letras, FCLAr-UNESP, CEP: 14800901, Araraquara - SP, Brasil, e-mail: bizelli@ fclar.unesp.br
} 
Informações fluem em grandes quantidades e a velocidades surpreendentes, exigindo dos atores sociais um processo contínuo e profundo de formação que os habilite a transitar pelos novos conhecimentos. As mudanças são tão intensas que até mesmo os conceitos de tempo e espaço se modificam (LESSA, 2011).

Sob o olhar do Ensino a Distância (EAD) - marcado por processos que inserem as TIC nas relações ensino-aprendizagem -, as noções de tempo e de espaço são relativizadas já que a "aula" não possui locais ou horários definidos, a aprendizagem vai acontecendo conforme os interesses e necessidades de professores e seus alunos (CASTRO, 2007).

Informação contínua a ser obtida a qualquer hora modificando as relações de aprendizagem, possibilitando o renascimento do EAD (LESSA, 2011).

\section{O Ensino a Distância: definições}

$\mathrm{O}$ EAD acontece quando aluno e professor não estão presencialmente em uma instituição de ensino, participando de atividades e interagindo como uma classe tradicional. Castro (2007) afirma que o EAD absorve um processo de ensino-aprendizagem que não implica na presença física do professor indicado para ministrá-lo no lugar onde é recebido, ou um processo ensino-aprendizagem no qual o professor está presente apenas em certas ocasiões ou para determinadas tarefas.

Moore e Kearley (2008) concordam com essa ideia e definem os processos de Educação a Distância como situações nas quais alunos e professores, em locais diferentes, durante todo ou grande parte do tempo, estabelecem uma relação de ensino-aprendizagem. Acrescentam, porém, que como as figuras de professor e aluno estão em locais distintos, torna-se necessário o uso de algum tipo de tecnologia para transmitir informações e lhes proporcionar um meio para interagir:

Educação a distância é o aprendizado planejado que ocorre normalmente em um lugar diferente do local de ensino, exigindo técnicas especiais de criação do curso de instrução, comunicação por meio de várias tecnologias e disposições organizacionais e administrativas especiais (MOORE e KEARLEY, 2008, p.2).

Algo muito questionado em relação ao EAD é o fato de não possuir, necessariamente, a presença física do professor em sala de aula. Porém, isso não diminui em nada a eficácia do $\mathrm{EaD}$ no que diz respeito ao processo de ensino-aprendizagem. Pelo contrário, a capacidade do professor de entender, mediar e estimular os alunos através das novas tecnologias disponíveis deve ser ainda maior. O esforço de ambas as partes torna-se essencial para que a transmissão do conhecimento aconteça de forma eficaz. 
Em tempos de TIC, o conceito de educação precisa ser ampliado. O processo de ensino-aprendizagem deve envolver mídias como rádio, televisão analógica, internet e televisão digital, contando com todas as potenciais possibilidades dos videojogos, dos rádios digitais e dos celulares. Isso agrega novos valores ao aprendizado, tornando os alunos coparticipantes da construção do conhecimento.

\section{Passagem Histórica do EAD}

Para entender o EAD, hoje, é necessário analisar seu contexto histórico, pois ao contrário do que muitos pensam, esta modalidade de ensino surgiu muito antes da popularização da Internet. Desta forma, Moore e Kearley (2008) dividiram a evolução da EAD em cinco gerações, que ilustram a sua evolução ao longo dos anos.

- Primeira Geração: chamada de "Geração Textual” teve início em 1880, utilizava as correspondências para a transmissão do conhecimento. O objetivo dos primeiros educadores por correspondência era usar a tecnologia da época, os serviços postais, para chegar até aqueles que, de outro modo, não poderiam se beneficiar dela.

- Segunda Geração: chamada de "Geração Analógica" teve início na década de 30, realizava sua transmissão por meio de rádio e televisão. O rádio não atendeu às expectativas devido aos diferentes interesses entre emissoras e instituições de ensino. Já a televisão, com as TVs educativas, obteve mais sucesso por conta de contribuições empresariais. Nesta geração foram oferecidos tanto cursos de curta-duração, como cursos de nível superior e surgiu a transmissão de cursos pela TV a cabo e os chamados Telecursos, que integravam programas de televisão com livros didáticos.

- Terceira Geração: chamada de "Geração das Tecnologias de Comunicação" se iniciou no final da década de 60, foi caracterizada por mudanças significativas. Surgiu o Projeto de Mídia de Instrução Articulada (AIM - Articulated Instructional Media Project), que agrupava várias tecnologias de comunicação para propagar o ensino com custo reduzido. As tecnologias utilizadas eram materiais impressos, correspondência para orientações, transmissão por rádio e televisão, conferências por telefone, kits para experiências em casa e recursos de bibliotecas locais. Ainda nesta geração, em 1967, foram criadas as Universidades Abertas (UAs) que usavam o rádio e a televisão para transmitir seus conteúdos.

- Quarta Geração: chamada de "Geração da Teleconferência" surgiu nos Estados Unidos em 1980 e era baseada na tecnologia da teleconferência e, portanto, era elaborada para o uso de grupos. Era um modo mais próximo ao ensino tradicional, pois os alunos se 
reuniam em salas de aula convencionais ou outras localidades como residências e empresas. $\mathrm{Na}$ década de 90, surgiu a videoconferência se possibilitou a comunicação nos dois sentidos.

- Quinta Geração: chamada de "Geração Digital”, em que estamos inseridos até os dias de hoje, está apoiada nas novas TIC e sua principal característica, a possibilidade de estabelecer maior interatividade entre aluno e professor. Como maior exemplo das novas TIC, temos a internet e a televisão digital.

\section{Legislação Brasileira da EAD}

Antes de discutir a legislação brasileira do EAD, faz-se necessário esclarecer dois termos utilizados para definir os atos normativos no nosso país, são eles: Lei e Decreto. Para a formação de uma lei, os Poderes Legislativo e Executivo, formados respectivamente por parlamentares e Presidente da República, trabalham em conjunto. O Poder Legislativo apresentando o projeto de lei e o Poder Executivo, sancionando-o e transformando em lei. Já um decreto é editado pelo Presidente e não depende do Congresso Nacional, pois não passa por discussão do legislativo. O decreto tem suas limitações, pois não tem força para modificar uma lei, sua função é apenas regulamentá-la. (LESSA, 2011)

3.1 O Art. 80 da Lei de Diretrizes e Bases da Educação - LBD (Lei 9.394) de 20 de Dezembro de 1996.

Apesar dos muitos anos de história, como citado anteriormente, a primeira menção oficial sobre a EAD ocorreu apenas em 1996, na Lei de Diretrizes e Bases da Educação. O texto apresenta claramente o incentivo do Poder Público à implementação de cursos desta modalidade:

Art. 80. O Poder Público incentivará o desenvolvimento e a veiculação de programas de ensino a distância, em todos os níveis e modalidades de ensino, e de educação continuada. (BRASIL, 1996)

Esta lei foi responsável por dar um novo status à EAD, atribuindo legitimidade e visibilidade. Assim, a partir de 1996, com a promulgação da lei, a EAD passou a ser considerada alternativa regular de prestação educacional aos brasileiros, deixando de ser uma alternativa permanentemente experimental ou concebida como solução paliativa para atender os excluídos. 
Porém, apesar da sua menção na LBD, a alternativa permanecia apenas anunciada e o texto remetia a futuras regulementações, advindas de decretos regumentadores. (LOBO NETO, 2006)

\subsection{O Decreto 5.622, de 19 de dezembro de 2005 .}

Dando continuidade à elaboração da leigislação da EAD no Brasil, o Poder Executivo Federal procurou baixar um decreto que regulamentaria a Art. 80 da LDB. Alguns textos foram baixados e revogados, pois "eram tímidos para um Brasil moderno", segundo Alves (2006).

Foi baixado, então, o decreto 5622/05 que está dividido em seis capítulos e contém 37 artigos com muitos parágrafos e incisos. A seguir serão pontuados os principais apectos do decreto, a partir dos estudos de Alves (2006). Assim, resumidamente, o Decreto contempla:

a) A possibilidade de mestrados e doutorados a distância, um aspecto extremamente positivo para a EAD no país;

b) $\mathrm{O}$ credenciamento de instituições de pesquisa tanto científica quanto tecnológica para programas de EAD e não apenas instituições de ensino, o que abre um leque maior de variedade de oferta de programas;

c) Desrespeito à autonomia universitária quando exige credenciamento das universidades por parte da União, o que desrespeita o Art. 80 da LBD, que assegura a autonomia das universidades em criar cursos;

d) $\mathrm{O}$ ensino fundamental e médio regulares não são contemplados no decreto, deixando a orientação da modalidade voltada para educação de jovens e adultos;

e) A limitação geográfica dos alunos de $\mathrm{EAD}$, contrariando o princípio mundial da EAD de nacionalização dos cursos e programas;

f) Duração dos programas de EAD iguais aos dos programas presenciais, que torna a modalidade inflexível e sem a possibilidade de aceleração da aprendizagem;

g) Exigência de momentos presenciais, contrariando os conceitos da moderna EAD presente na atual Sociedade da Informação.

O último aspecto citado é o que mais recebe críticas de estudiosos da área. Como é possível observar no texto encontrado no Art. 1 do Capítulo 1 do Decreto 5.622/05. É clara a exigência de momentos presenciais na modalidade EAD. 
$\S 1^{\circ}$ A educação a distância organiza-se segundo metodologia, gestão e avaliação peculiares, para as quais deverá estar prevista a obrigatoriedade de momentos presenciais para: I - avaliações de estudantes; II - estágios obrigatórios, quando previstos na legislação pertinente; III - defesa de trabalhos de conclusão de curso, quando previstos na legislação pertinente; e IV - atividades relacionadas a laboratórios de ensino, quando for o caso. (BRASIL, 2005)

Este artigo caracteriza a EAD, restringindo o que é obrigatório acontecer de forma presencial: a avaliação, o estágio, a defesa de trabalhos e, eventualmente, a atividade em laboratório. Isso limita ainda mais a EAD, afinal a flexibilidade, uma das principais vantagens ofertadas pela $\mathrm{EAD}$, acaba sendo comprometida por esta determinação.

Além disso, o artigo $4^{\circ}$ deixa claro que a prova presencial deve prevalecer sobre os outros elementos que compõem a avaliação, cuja execução seja feita a distância (trabalhos, participação em atividades, realização de tarefas, etc.).

Art. $4^{\circ} \mathrm{A}$ avaliação do desempenho do estudante para fins de promoção, conclusão de estudos e obtenção de diplomas ou certificados dar-se-á no processo, mediante: I - cumprimento das atividades programadas; e II realização de exames presenciais. $\S^{\circ}$ Os exames citados no inciso II serão elaborados pela própria instituição de ensino credenciada, segundo procedimentos e critérios definidos no projeto pedagógico do curso ou programa. $\$ 2^{\circ}$ Os resultados dos exames citados no inciso II deverão prevalecer sobre os demais resultados obtidos em quaisquer outras formas de avaliação a distância. (BRASIL, 2005)

Segundo Lobo Neto (2006), a partir do momento que se exige a presença do aluno no EAD, duvida-se de sua eficácia como modalidade de ensino colocando-o em posição inferior. Segundo o autor o EAD possui meios altamente confiáveis, operacionalizados pela tecnologia disponível, para avaliação e controle de seus programas. E tal obrigação engessa a evolução da modalidade e inviabiliza projetos inovadores.

Em nenhum momento a lei autoriza a considerar cursos a distância como semicursos, cursos de segunda categoria ou 'meios informais' de aprendizagem, cuja proposta pedagógica não é nunca suficientemente qualificada para, no processo - e afirme-se, com todas as letras, também a distância -, verificar e avaliar o desempenho dos alunos. Porque - cabe repetir - no processo e também a distância é possível verificar e avaliar a capacidade de construir e reconstruir conhecimento, de aplicar conhecimento à solução de problemas, praticar ações e procedimentos, de manifestar atitudes e comprometimento com valores. A questão de sair-se - ao arrepio da lei - em busca do presencial como garantia de verificação e avaliação eficaz e séria é expediente preguiçoso e falacioso de isentar-se da busca dos meios capazes de superar a distância. (LOBO NETO, 2006, p. 412) 
Para Chiantia (2008), essa exigência não estabelece ligação com o espírito do ensino na sua modalidade a distância. Por exigir "momentos presenciais", descaracteriza a essência do art. 80 da LDB que estabelece: “O Poder Público incentivará o desenvolvimento e a veiculação de programas de ensino a distância, em todos os níveis e modalidades de ensino, e de educação continuada".

Porém há autores que observam a exigência de momentos presenciais, como positiva e uma preocupação do legislador com a qualidade da modalidade.

É possível perceber, portanto, a preocupação constante com a realização de avaliações presenciais, as quais são consideradas na legislação vigente como um fator preponderante para a garantia da qualidade dos cursos ofertados na modalidade de educação a distância, devendo ser cercadas das precauções de segurança, zelando pela confiabilidade e credibilidade dos resultados. (LESSA, 2011, p. 24)

Lessa (2011) afirma também que a legislação da EAD sempre procurou formas de garantir legitimidade e autenticidade da avaliação. E, objetivando afastar fraudes, a avaliação presencial deve ser considerada como fundamental para aprovação do aluno.

\section{Considerações Finais}

O presente artigo evidenciou alguns apontamentos importantes sobre o EAD no âmbito de sua história e legislação. Sob o aspecto histórico, foi possível observar que esta antiga modalidade de ensino surgiu para atender alunos que tivessem dificuldades, em vários aspectos, de acesso à educação tradicional. Foi possível observar também, que a evolução da EAD está totalmente relacionada com a evolução tecnológica da sociedade, que trouxe novas configurações em suas formas de implantação.

Sob o aspecto legislativo, é perceptível que a demora em regulamentar acabou por caracterizar a EAD, para muitos, como uma alternativa inferior de ensino. Assim, por muito tempo a EAD foi vista apenas como um "estepe", utilizado somente quando as modalidades presenciais de educação falhavam. Com isso, as pessoas criaram uma visão negativa sobre sua metodologia, considerando-a como um sistema dirigido somente para uma parcela desfavorecida (financeiramente ou intelectualmente) da população.

Assim, quando em 1996 aparece, pela primeira vez, a menção da EAD na legislação brasileira, através da Lei de Diretrizes e Bases da Educação, inicia-se um longo processo ainda longe do fim - de tornar o EAD uma possibilidade real de democratização da educação no Brasil. E o primeiro obstáculo para alcance desta realidade é, a já citada, 
imagem negativa que muitos possuem sobre a modalidade, que levanta dúvidas sobre sua qualidade. Segundo Lemes e Souza (2014, p. 24/25) a questão agora é de como complementar a democratização das oportunidades pela democratização qualificada da própria escola, instituindo um padrão de ensino que atenda essa demanda e supere os desafios que essa nova realidade apresenta. Os autores apontam a existência de desafios de grande complexidade ao sistema de ensino, que para serem respondidos devem contar com procedimentos que atendam em quantidade e qualidade suas exigências e peculiaridades. Tais ações impõem, no campo paradigmático, a necessidade de novos conhecimentos e domínios epistemológicos. Sendo um processo dinâmico necessitam demonstrar eficiência frente aos objetivos da demanda educacional inclusiva e não excludente.

Em diversos países, o EAD já é reconhecido como meio de Educação de qualidade e como alternativa à modalidade presencial, uma vez que há muitos indivíduos que, pelos mais diferentes motivos, não conseguem atingir o nível de conhecimento desejado pelos meios tradicionais. No Brasil, embora avanços tenham acontecido nos últimos anos, ainda há um caminho a percorrer para que ele possa ocupar um espaço de destaque no meio educacional em todos os níveis, vencendo, inclusive, preconceitos.

Segundo Lessa (2011, p.20) "Essa atitude é fruto da desconfiança e ignorância que reduz o conceito de EAD ao elementarismo dos cursos técnicos por correspondência, sem controle de aprendizado e sem regulamentação adequada".

O preconceito existe, mas não só contra o $\mathrm{EAD}$, mas também contra tudo aquilo que não se conhece ou que não se sabe como trabalhar e que envolve novos processos de aprendizagem e mudança de posturas. Assim, todas as normas criadas nos últimos anos, objetivam trazer segurança à sociedade, para desmistificar a falsa ideia de que existe diferença de qualidade entre curso da modalidade presencial e a distância (LESSA, 2011).

Referente à utilização da modalidade como uma alternativa de democratizar o acesso à Educação, Lobo Neto (2006, p. 413) afirma que "a educação a distância só tem sentido quando se realiza como ampliação das possibilidades de acesso à educação, apresentando-se como uma alternativa de democratização da educação e do conhecimento".

É preciso, então, ter muita clareza sobre as condições de ter o EAD como alternativa de democratização do ensino. Do ponto de vista social, o EAD, como qualquer forma de educação, não apenas deve pretender ser, mas precisa concretamente realizar-se como uma prática social significativa (LOBO NETO, 2006).

Assim, é possível concluir que a democratização do acesso à Educação pode ser realizada através do $\mathrm{EAD}$, porém tal realidade está condicionada à revisão das normas 
regulatórias da modalidade, tornando-as mais flexíveis, menos restritiva e livre de dúvidas quanto ao seu potencial para ensinar. Ainda há muito trabalho a ser feito para que o EAD seja, efetivamente, um dos meios mais importantes para se democratizar a Educação de qualidade no Brasil.

\section{Referências}

ALVES, João Roberto Moreira. A Nova Regulamentação da EAD no Brasil. In: SILVA, Marco (Org) Educação online. São Paulo: Loyola, 2006.

BIZELLI, José Luís; CARAM, Nirave Reigota. Ensino a Distância através da Televisão Digital: desafios e possibilidades. In: HEREDERO, E. S.; BRIS, M. M.; VÁSQUEZ, V. A. (Org.). Reflexiones y realidades sobre Educación desde la perspectiva Iberoamericana. Santillana: Santiago do Chile, p. 79-98, 2012.

BIZELLI, José Luís. Inovação: limites e possibilidades para aprender na Era do Conhecimento. São Paulo: Editora Unesp/Cultura Acadêmica, 2013.

BRASIL. DECRETO N. ${ }^{0}$ 5.622/05. Regulamenta o art. 80 da Lei $n^{\circ}$ 9.394, de 20 de dezembro de 1996, que estabelece as diretrizes e bases da educação nacional. Disponível em http://www.planalto.gov.br/ccivil_03/_Ato2004-2006/2005/Decreto/D5622.htm. Acesso em 17 de setembro de 2013.

LEI $\mathbf{N}^{\circ}$ 9.394/96. Estabelece as diretrizes e bases da educação nacional. Disponível em http: http://www.planalto.gov.br/ccivil_03/leis/19394.htm. Acesso em 17 de setembro de 2013.

CASTRO, Cosette. EAD e TV Digital: A co-autoria na aprendizagem. In: TV Digital: Qualidade e Interatividade. Brasília: Confez/CNI, 2007.

CHIANTIA, Fabrizio Cezar. Parecer: Qual o amparo legal para a Educação a Distância no Brasil? Associação Brasileira de Educação a Distância, ABED. 2008. Disponível em: <http://www2.abed.org.br/documentos/ArquivoDocumento255.pdf>. Acesso em: $02 \mathrm{de}$ setembro de 2013.

LEMES, Sebastião de S. e SOUZA, Cláudio B. Gomide de (in memoriam). Tecnologia e escolarização em contexto de democratização do sistema educacional: relações possíveis e discussões necessárias. In Faces da Escola em Ibero-América. Bizelli, José L. e Souza, Cláudio B. Gomide de (in memoriam), Org. Série Temas em Educação Escolar - n 20; São Paulo, Cultura Acadêmica, 2014.

LESSA, Shara Christina Ferreira. Os Reflexos da Legislação da Educação a Distância no Brasil. In: Revista Brasileira de Aprendizagem Aberta e a Distância. Volume 10. 2011. Disponível

em: http://www.abed.org.br/revistacientifica/Revista_PDF_Doc/2011/Artigo_02.pdf. Acesso em: 17 de setembro de 2013.

LOBO NETO, Francisco José da Silveira. Regulamentação da educação a distância: caminhos e descaminhos. In: SILVA, Marco (Org) Educação online. São Paulo: Loyola, 2006.

MATURANO. Ediane Carolina Peixoto Lopes. Educação a Distância e as Políticas Educacionais a partir dos Anos Noventa: alguns apontamentos na discussão. Dissertação de Mestrado. FCLar/Unesp, sob orientação do prof. Dr. Sebastião de Souza Lemes, 2013. 
MOORE, Michael G. Educação a Distância: uma visão integrada. Michael G. Moore, Greg Kearsley; [tradução Roberto Galman]. - São Paulo: Thomsom Learning, 2007.

MUGNOL, Márcio. A Educação a Distância no Brasil: conceitos e fundamentos. Rev. Diálogo Educ: Curitiba, 2009.

SILVA, P. R. B. da. A Percepção Docente sobre o Modelo de Educação Semipresencial utilizado no Telecurso Tec: um programa de qualificação e habilitação técnica de nível médio, oferecido em escolas da rede pública estadual de educação. Centro Estadual de Educação Tecnológica Paula Souza, São Paulo, 2009.

SIMÃO, Lílian O. Estudo de Tecnologias Aplicadas à Educação a Distância. Dissertação de Mestrado. Instituto de Ciências Matemáticas e de Computação, Universidade de São Paulo, São Carlos, 2011. 